\title{
REVIEW
}

\section{Shedding light on the intricate puzzle of ghrelin's effects on appetite regulation}

\author{
Blerina Kola and Márta Korbonits \\ Endocrinology, William Harvey Research Institute, Barts and the London School of Medicine and Dentistry, Centre for Endocrinology, Queen Mary University of \\ London, Charterhouse Square, London EC1M 6BQ, UK \\ (Correspondence should be addressed to M Korbonits; Email: m.korbonits@qmul.ac.uk)
}

\begin{abstract}
Ghrelin, a hormone primarily produced by the stomach, has a wide range of metabolic and non-metabolic effects. It also stimulates food intake through activation of various hypothalamic and brain stem neurons. A series of recent studies have explored the intracellular mechanisms of the appetite-inducing effect of ghrelin in the hypothalamus, shedding light on the intricate mechanisms of appetite regulation. AMP-activated protein kinase (AMPK) is a key metabolic enzyme involved in appetite regulation.
\end{abstract}

Calmodulin kinase kinase 2 (CaMKK2) has been identified as an upstream kinase of AMPK and a key mediator in the effect of ghrelin on AMPK activity. The fatty acid pathway, hypothalamic mitochondrial respiration, and uncoupling protein 2 have been outlined as downstream targets of AMPK and mediators of ghrelin's appetite stimulating effect. This short overview summarises the present data in this field.

Journal of Endocrinology (2009) 202, 191-198

\section{Introduction}

Ghrelin, a peptide produced mainly by the oxyntic cells of the stomach, was identified as the natural ligand of the GH secretagogue receptor (GHSR) in 1999 (Kojima et al. 1999). Over the last decade, a myriad of studies have investigated its wide-ranging effects on the regulation of $\mathrm{GH}$ secretion, on immune function, cognition, gonadal axis regulation, bone metabolism, gastrointestinal motility, cell proliferation, and the cardiovascular system (Higgins et al. 2007). Ghrelin is considered a 'hunger' hormone, as its levels increase with fasting and fall post-prandially (Cummings et al. 2001, Shiiya et al. 2002). Ghrelin not only stimulates appetite but also affects peripheral glucose and lipid metabolism as well as energy expenditure, in a way that leads to the accumulation and preservation of energy stores (Tschöp et al. 2000, Theander-Carrillo et al. 2006). Ghrelin is thought to modulate the expression of hypothalamic neuropeptides such as neuropeptide Y (NPY) and agouti-related peptide (AgRP) within the arcuate nucleus (ARC) and melaninconcentrating hormone in the lateral hypothalamus (Seoane et al. 2003, Smith et al. 2005, Egecioglu et al. 2008). The GHSR is mainly expressed in the ARC, the ventromedial $(\mathrm{VMN})$ and the paraventricular nuclei (PVN) in the hypothalamus, as well as in the area postrema, the nucleus of the solitary tract (NTS), the dorsal motor nucleus of the vagus and the parasympathetic preganglionic neurons (Bennett et al. 1997, Guan et al. 1997, Zigman et al. 2005). GHSR is often located on presynaptic nerve endings, directly influencing neurotransmitter release. It couples to the $\mathrm{G}_{\mathrm{q} 11}$ protein and the phospholipase $\mathrm{C}$ (PLC)-protein kinase $\mathrm{C}$ (PKC) pathway to increase intracellular $\mathrm{Ca}^{2+}$ levels.

Ghrelin has a unique fatty acid modification on its $\mathrm{N}$-terminal end as a result of the activity of the ghrelin O-acyltransferase enzyme (Yang et al. 2008). However, the majority of circulating ghrelin is actually lacking this acyl group, and is known as des-acyl or des-octanoyl ghrelin. Des-acyl ghrelin has been shown to have various metabolic effects and controversial data has been published regarding its influence on appetite (Higgins et al. 2007). Our animal study showing no AMP-activated protein kinase (AMPK) response to i.c.v. des-acyl ghrelin (Kola et al. 2005) support the human data of no effect of des-acyl ghrelin on appetite (Neary et al. 2006). The full-length subtype 1a GHSR stands as the main receptor reported to mediate the orexigenic and $\mathrm{GH}$ actions of ghrelin. However, studies with synthetic GHSR agonists and antagonists have pointed to additional receptors being involved in conveying the hypothalamic and metabolic actions of ghrelin and suggesting that the GHSR may not be the only receptor which is activated by ghrelin (Higgins et al. 2007). 


\section{AMPK and ghrelin}

A new era in the field of appetite research was opened with the identification of AMPK as a major player in the regulation of food intake (Minokoshi et al. 2004). AMPK is a highly conserved enzyme which senses changes in the cellular AMP/ ATP ratio, and once activated switches on catabolic, ATPproducing processes, and switches off ATP-consuming anabolic processes (Kola et al. 2006). AMPK is activated by phosphorylation on the Thr172 residue by upstream kinases LKB1 and calmodulin kinase kinase 2 (CaMKK2; Hawley et al. 2005, Woods et al. 2005), but recent data also suggest a role in certain circumstances for transforming growth factor$\beta$-activated kinase (Suzuki et al. 2004, Hawley et al. 2005, Woods et al. 2005, Momcilovic et al. 2006) and ataxiatelangiectasia mutated gene (Suzuki et al. 2004). Recent data suggest that increased AMP does not directly promote phosphorylation of Thr172 by upstream kinases but rather inhibits the dephosphorylation of AMPK by protein phosphatase-2C- $\alpha$ (PP2C- $\alpha$; Sanders et al. 2007, Lage et al. 2008). A new model of AMPK regulation, independent of AMP, has emerged with the finding that the cell death inducing DFFA-like effector A (Cidea) by forming a complex with the $\beta$-subunit of AMPK, elicits an ubiquination-mediated degradation of AMPK (Lage et al. 2008, Qi et al. 2008).

AMPK seems to mediate the orexigenic and anorexigenic effect of a multitude of hormones and compounds including leptin, insulin, glucose, cannabinoids, adiponectin, glucocorticoids, thyroid hormones, metformin, $\alpha$-lipoic acid, $\alpha-\mathrm{MSH}, \mathrm{MT}-\mathrm{II}$, and ciliary neutrophic factor (Kola et al. 2006, Kubota et al. 2007, Kola 2008). Ghrelin is not an exception to this rule. We and others have shown that both central (i.c.v.) and peripheral (i.p.) ghrelin treatment stimulate AMPK activity in the hypothalamus, leading to ghrelin's well known orexigenic effect (Andersson et al. 2004, Kola et al. 2005). Recently, the signalling pathway of ghrelin's orexigenic effect in the hypothalamus has been further elucidated with the identification of CaMKK2 as the relevant upstream kinase of AMPK (Anderson et al. 2008), and with the identification of the endocannabinoid(Kola et al. 2005, 2008) and the fatty acid pathways (Lopez et al. 2008) as well as the mitochondrial uncoupling protein 2 (UCP2)- (Andrews et al. 2008) as novel downstream effectors of ghrelin. We review here the pathway which is now emerging from the recently described data: ghrelinGHSR $-\mathrm{Ca}^{2+}$-endocannabinoids-cannabinoid receptor type 1 (CB1)-Ca ${ }^{2+}$-CaMKK-AMPK-malonyl-CoA-carnitine palmitoyltransferase 1 (CPT1)- $\beta$-oxidation-reactive oxygen species (ROS)-UCP2-NPY/AgRP-food intake (Fig. 1).

\section{Ghrelin stimulates CaMKK2}

The ghrelin receptor GHSR, a $G_{\mathrm{q}}$-coupled receptor, increases intracellular $\mathrm{Ca}^{2+}$ via PLC and PKC activation and the rise in intracellular $\mathrm{Ca}^{2+}$ could in principle lead to
CaMKK2 activation. It was therefore postulated that the stimulatory effect of ghrelin on hypothalamic AMPK might be mediated through CaMKK2 (Anderson et al. 2008). The mRNA for CaMKK2 was found to be highly expressed in the ARC, 20-40-fold more than in other hypothalamic areas. CaMKK2 knockout mice (CaMKK2-KO) showed reduced expression of NPY and AgRP, but no differences in pro-opiomelanocortin (POMC) expression, suggesting a role for CaMKK2 only in the orexigenic NPY neurons. Modulation of AMPK activity has been shown to regulate NPY expression (Minokoshi et al. 2004). In agreement with the above results, hypothalamic AMPK activity was also reduced in the CaMKK2-KO mice (Anderson et al. 2008). Systemic ghrelin injection, which increased food intake in wild-type (WT) animals, failed to do so in the CaMKK2-KO mice. In addition, STO-609, a selective CaMKK2 inhibitor, inhibited NPY expression and reduced food intake and body weight in WT animals. A key finding of this study was the demonstration of a unique complex comprising CaMKK2, AMPK- $\alpha / \beta, \mathrm{Ca}^{2+}$, calmodulin, and acetyl-CoA carboxylase (ACC). CaMKK2 forms a stable complex containing the $\alpha$ and $\beta$ subunits of AMPK (but not the $\gamma$ subunits), although this stable complex between CaMKK2 and AMPK is not necessarily required for the kinase-substrate (i.e., CaMKK2-AMPK) interaction (Anderson et al. 2008).

The finding that CaMKK2 is the upstream AMPK kinase in the hypothalamus, mediating the stimulatory effect of ghrelin on the enzyme, suggests the possibility that CaMKK2 might be involved in the effects of ghrelin in other tissues. This also brings up the interesting question as to why ghrelin, which acts through a $\mathrm{G}_{\mathrm{q}}-$ coupled receptor and consequent increases in intracellular $\mathrm{Ca}^{2+}$ in all tissues, has a tissue-specific effect on AMPK, stimulating it in the hypothalamus and myocardium, and inhibiting it in liver and adipose tissue (Kola et al. 2005)? We also need to bear in mind the fact that several other AMPK regulators also have a tissue-specific effect, most notably leptin. Ghrelin might affect PP2C- $\alpha$, a known dephosphatase of AMPK, and the final effect on AMPK activity, could be due to an altered balance between CaMKK2-induced activation and PP2C- $\alpha$-induced inactivation of AMPK. While the study from Anderson et al. (2008) clearly shows that ghrelin-induced AMPK activation is dependent on an increase in intracellular $\mathrm{Ca}^{2+}$ and consequent activation of CaMKK2, another recent report suggested that ghrelin increases intracellular $\mathrm{Ca}^{2+}$ levels in the ARC NPY neurons via AMPK-mediated signalling, as the AMPK inhibitor, compound $\mathrm{C}$, was able to suppress ghrelin's effect on intracellular $\mathrm{Ca}^{2+}$ levels (Kohno et al. 2008). Thus, changes in intracellular $\mathrm{Ca}^{2+}$ can activate CaMKK2 which then seems to modulate AMPK activity, while on the other hand AMPK status seems to influence intracellular $\mathrm{Ca}^{2+}$ levels, suggesting a positive feedback loop between AMPK and $\mathrm{Ca}^{2+}$. However, we believe that the majority of the data support 


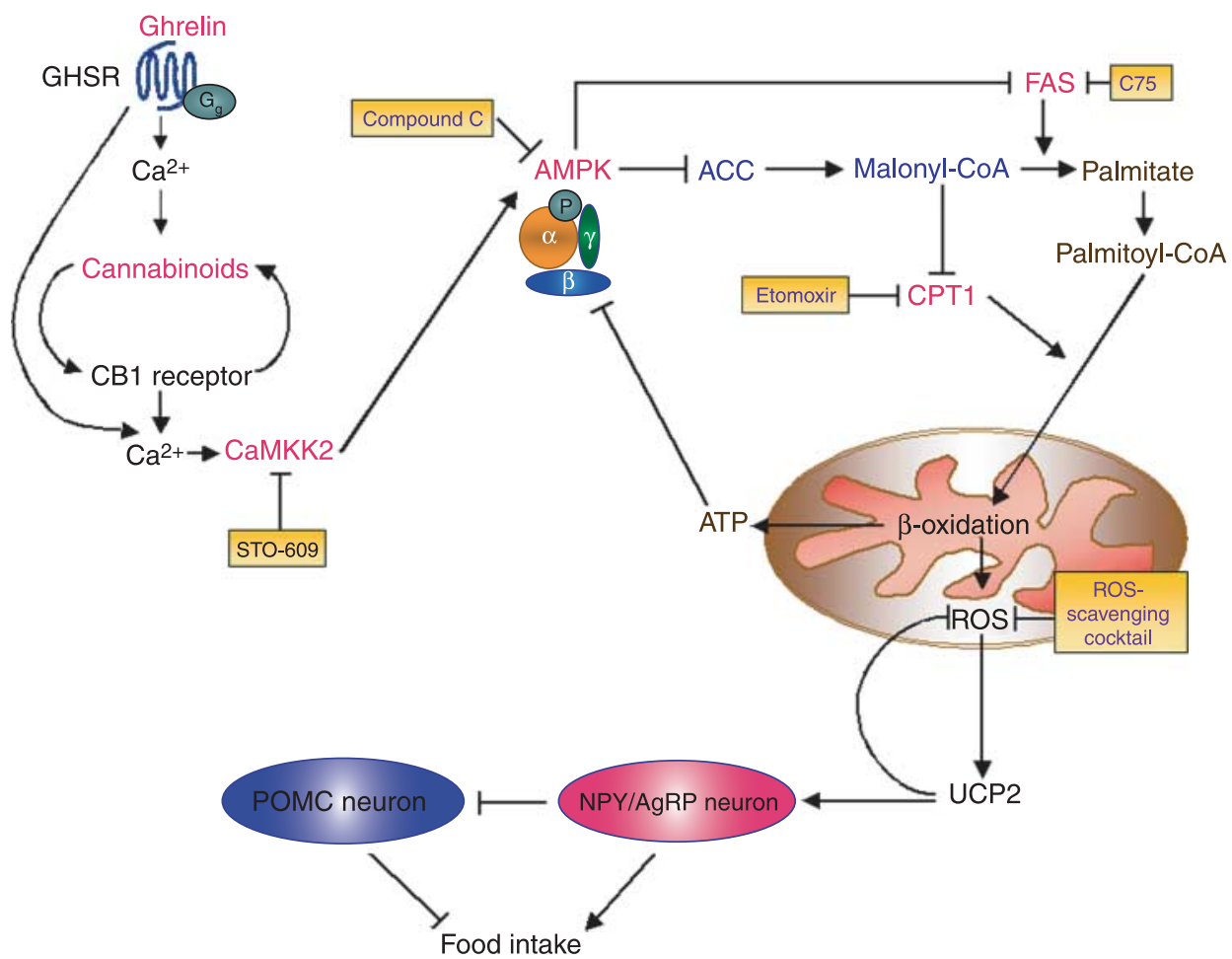

Figure 1 Schematic diagram showing the proposed molecules involved in the appetite-inducing effect of ghrelin. The activation of molecules highlighted in red leads to increased food intake, whereas the activation of molecules highlighted in purple leads to inhibition of food intake. In this figure, we have depicted a simplified, linear relationship among the elements comprising the ghrelin signalling cascade. Clearly, the different components of this cascade can also interact within and outside this pathway, activating other distinct downstream signalling components, here not reported, either sequentially or simultaneously, suggesting a much more complex regulation. This figure has been drawn based on the studies of Andersson et al. (2004), Landree et al. (2004), Kola et al. (2005, 2008), Anderson et al. (2008), Andrews et al. (2008) and Lopez et al. (2008). GHSR, GH secretagogue receptor; CaMKK, calmodulin kinase kinase; CB1, cannabinoid receptor type 1; AMPK, AMP-activated protein kinase; ACC, acetylcoenzyme A carboxylase; malonyl-CoA, malonyl coenzyme A; FAS, fatty acid synthase; CPT1, carnitine palmitoyl transferase 1; ROS, reactive oxygen species; UCP2, uncoupled protein 2; NPY, neuropeptite Y; AgRP, agouti-related peptide; POMC, pro-opiomelanocortin.

the first possibility as being the primary mechanism, i.e., that ghrelin stimulates $\mathrm{Ca}^{2+}$ entry and that AMPK is downstream from this $\mathrm{Ca}^{2+}$ signal.

\section{Ghrelin's effect via the fatty acid pathway}

The downstream effectors of the ghrelin-GHSR-CaMMK2AMPK axis in the regulation of feeding have been elucidated by Lopez et al. (2008) who showed that ghrelin regulates feeding through an AMPK-dependent inhibition of the de novo fatty acid synthesis pathway in the VMN. Several recent pharmacological and genetic studies have demonstrated that components of the fatty acid metabolism pathways modulate the regulation of hypothalamic feeding (Loftus et al. 2000, Obici et al. 2003, Lopez et al. 2006, Wolfgang et al. 2006, Chakravarthy et al. 2007). AMPK is an important regulator of the fatty acid biosynthetic pathway: AMPK phosphorylates and inhibits ACC, preventing the production of malonylCoA. This stimulates CPT1 and the transport of fatty acids into the mitochondria, ultimately facilitating mitochondrial fatty acid oxidation (Fig. 1).

Ghrelin's orexigenic effect is AMPK-dependent as both compound $\mathrm{C}$, an inhibitor of AMPK, and adenoviruses harbouring $\alpha-1 / \alpha-2$ dominant negative AMPK were able to prevent it (Lopez et al. 2008). Ghrelin's stimulatory effect on food intake was paralleled by a decrease in fatty acid synthase (FAS) mRNA levels in the VMN, as well as a decrease in total hypothalamic FAS activity and protein levels, in fed rats after $6 \mathrm{~h}$ of treatment. Co-expression of FAS and GHSR was also found in the ARC and in the PVN at lower levels than in the VMN, but no significant changes were found in FAS mRNA levels in these hypothalamic nuclei or in other brain areas. 
Compound $\mathrm{C}$ and stereotactic delivery of $\alpha-1 / \alpha-2$ dominant negative AMPK adenoviruses in the VMN also prevented the ghrelin-induced decrease in FAS mRNA levels, demonstrating that the ghrelin effect on FAS mRNA expression is mediated by an AMPK-dependent mechanism (Lopez et al. 2008). The relationship between AMPK and FAS seems to obey the rules of feedback regulation. The study from Lopez et al. places FAS clearly as a downstream target of AMPK, confirmed also by previous studies which have identified FAS as a downstream target of AMPK also in liver (Zhou et al. 2001), whereas previous studies suggested a regulation in the opposite direction as $\mathrm{C} 75$, an inhibitor of FAS, reduced AMPK phosphorylation; this probably occurs as a result of increased hypothalamic ATP levels, consequent of increased $\beta$-oxidation (Landree et al. 2004; Fig. 1). Nevertheless, it should be kept in mind that $\mathrm{C} 75$ is not a very specific inhibitor as it causes non-specific neuronal activation and its anorexigenic effect may not be explained by FAS inhibition alone (Takahashi et al. 2004).

Levels of malonyl-CoA are determined by three enzymes: by ACC, which stimulates its synthesis, by malonyl-CoA decarboxylase, which degrades it, and by FAS which converts it to fatty acids. Hypothalamic malonyl-CoA levels decreased $2 \mathrm{~h}$ after ghrelin treatment, returning to normal $6 \mathrm{~h}$ later. CPT1 was regulated in a similar time-dependent manner, as its activity was increased acutely at $2 \mathrm{~h}$ and was restored to normal levels $6 \mathrm{~h}$ after treatment. I.c.v. administration of etomoxir, an inhibitor of CPT1, decreased the orexigenic effect of ghrelin at $2 \mathrm{~h}$. This suggests that the stimulatory action of ghrelin on CPT1 activity may be mediated by simultaneous changes in malonyl-CoA levels.

Modulation of AMPK by leptin (Andersson et al. 2004), $\alpha$-lipoic acid (Kim et al. 2004) or ghrelin (Kola et al. 2005) is associated with decreased (leptin and $\alpha$-lipoic acid) or increased (ghrelin) phosphorylation of its downstream target ACC, leading to stimulation or inhibition of ACC activity. In support of this mechanism, degradation of malonyl-CoA in the medial basal hypothalamus of rats results in increased food intake and progressive weight gain (He et al. 2006), while inhibition of CPT1 in the hypothalamus suppresses food intake (Obici et al. 2003, Pocai et al. 2006; Fig. 1).

\section{Ghrelin acts via UCP2}

The further downstream steps of ghrelin on food intake were explored in a recent study by Andrews et al. (2008). Ghrelin increased the expression of hypothalamic CPT1 mRNA while etomoxir and compound $\mathrm{C}$ prevented the ghrelin-induced increase in both NPY and AgRP gene expression. It was suggested that ghrelin stimulates hypothalamic mitochondrial respiration via UCP2. Such an effect seems to mediate the activation of NPY/AgRP neurons, the synaptic plasticity of POMC-expressing neurons, and ghrelin-induced food intake.

UCPs are inner-membrane mitochondrial proteins which modulate energy expenditure via 'uncoupling' ATP generation, thereby dissipating the mitochondrial proton gradient necessary for ATP synthesis and generating heat (Wu et al. 1999). Ghrelin has previously been shown to enhance UCP2 mRNA expression in the pancreas (Sun et al. 2006), liver (Barazzoni et al. 2005), and white adipose tissue (Tsubone et al. 2005). In the Andrews' study, ghrelin was shown to increase hypothalamic UCP2 mRNA expression (Andrews et al. 2008). Mitochondrial respiration (nmol of oxygen consumed per minute per mg protein in isolated hypothalamic synaptosomes) and mitochondrial proliferation (number of mitochondria in NPY neuronal perikarya) were significantly increased in the ghrelin-treated WT mice, whereas no effect was present in UCP2-KO mice. Ghrelininduced NPY/AgRP mRNA expression and activation of NPY/AgRP neurons - as measured by c-fos expression and increased action potential - were also UCP2-dependent. Ghrelin had no effect on POMC neuronal action potential frequency or on POMC mRNA expression. Ghrelin indirectly hyperpolarizes POMC neurons by activating inhibitory NPY/AgRP inputs (Cowley et al. 2003) and, consistent with this, ghrelin treatment increased inhibitory synapses and significantly reduced the number of excitatory synapses on POMC neurons in WT but not in UCP2-KO. The UCP2-dependent effects on neuronal plasticity and activity translate into ghrelin's orexigenic effects, as UCP2$\mathrm{KO}$ mice do not increase food intake in response to either i.p. or intra-mediobasal hypothalamic ghrelin. Ghrelin's effect on AMPK activity was further confirmed by this study, and AMPK seems to lay upstream of UCP2, as the effect of ghrelin on the enzyme was still present in UCP2-KO mice. As proof of the hypothesis that AMPK requires UCP2 to exert an effect on feeding, the effect of the AMPK activator AICAR on food intake was lost in the UCP2-KO mice. The ghrelin-induced increase in UCP2 mRNA levels was diminished by concomitant i.c.v. administration of compound $\mathrm{C}$ or etomoxir placing the AMPK-CPT1 pathway upstream of UCP2. In agreement with this, ghrelin increases nonesterified fatty acid in the blood, providing a source of hypothalamic long chain fatty acids CoAs (LCFA-CoAs). There is initially an increase in the hypothalamic LCFA-CoAs after ghrelin treatment, followed by a reduction, suggesting that they undergo mitochondrial $\beta$-oxidation. UCP2 has the ability to reduce ROS levels, which are generated during mitochondrial $\beta$-oxidation. Concordant with this, ghrelin increased ROS production (as a result of the stimulation of the $\beta$-oxidation) in UCP2-KO mice but not in WT mice (where ROS production was stimulated but then buffered by UCP2). The authors propose that ghrelin-triggered ROS production promotes UCP2 mRNA expression and activity, and UCP2 then promotes ROS scavenging. In line with this, in UCP2$\mathrm{KO}$ mice, i.c.v. injection of a ROS-scavenging cocktail (which reduces ROS levels and therefore UCP2 activation) reversed the effects of ghrelin on NPY/AgRP mRNA levels, on mitochondrial uncoupled respiration, on NPY neuronal firing and on food intake. While the effect of leptin on food intake was not impaired in UCP2-KO mice, it would be 
interesting to see if other orexigenic or anorexigenic substances utilize the same pathway. We do not know, however, whether the energy released from the $\beta$-oxidation is the only way to influence the activity of these neurons. We are also unaware as to how UCP2 activation stimulates NPY/ AgRP transcription.

\section{Cannabinoid and ghrelin interaction}

Cannabinoids have been identified as yet another important link between ghrelin, AMPK, and appetite. AMPK that has now been confirmed to be involved in the regulatory pathways of many orexigenic and anorexigenic compounds also mediates the orexigenic effect of cannabinoids. Exogenous and endogenous cannabinoids induce food intake through the CB1 (Kirkham \& Tucci 2006) and stimulation of hypothalamic AMPK activity (Kola et al. 2005). More intriguing is the role that hypothalamic cannabinoids play in mediating the anorexigenic/orexigenic effects of hormones such as leptin and ghrelin (Di Marzo et al. 2001, Kola et al. 2008). Ghrelin and cannabinoid signalling pathways not only converge at the AMPK check-point, but also the interaction seems to take place at several levels. We have shown that ghrelin stimulates hypothalamic 2-AG and anandamide levels, suggesting that the effect of ghrelin on AMPK and the appetite inducing cascade, might be, at least in part, mediated by cannabinoids (Kola et al. 2008). The presence of an intact functional CB1 receptor is required for ghrelin's effect on AMPK activity and food intake as shown in CB1-KO animals as well as using a CB1 antagonist. Ghrelin inhibits excitatory synaptic input in the PVN and this effect is abolished with a CB1 antagonist as well as via inhibition of pre-synaptic cannabinoid synthesis (Kola et al. 2008). These data suggest that an intact endocannabinoid-CB1 pathway is necessary for ghrelin's effects.

\section{Summary}

Numerous studies aimed to characterize the mechanisms of hypothalamic appetite regulation, and to generate new possible molecular therapeutic targets, have contributed to the exploration of the signalling pathways of ghrelin. While often it is difficult to integrate the results of different studies, it seems that on the ghrelin issue there might be some agreement. The above reported studies lead us to draw a hypothetical intracellular pathway for ghrelin (Fig. 1). Fasting results in increased release of ghrelin from the stomach (the exact mechanism of this remains obscure) leading to increased plasma ghrelin levels, which reach the hypothalamus either via the blood stream directly in areas with no blood-brain barrier, or by crossing the blood-brain barrier via a saturable transport system or via the vagus nerve and the NTS. Ghrelin's effect on appetite is mediated by an effect both on the hypothalamus and the NTS.
Ghrelin increases Fos expression in the NTS at the level of the area postrema via a catecholaminergic-independent pathway (Faulconbridge 2008). Ghrelin, via GHSR, increases intracellular $\mathrm{Ca}^{2+}$ which stimulates the CaMKKAMPK-ACC-malonyl-CoA-CPT1 pathway, as noted above. However, it also leads to increased levels of intracellular cannabinoids, which additionally stimulate the AMPK-ACC pathway. The final result is increased mitochondrial $\beta$-oxidation with increased generation of ROS and stimulation of UCP2, which seems to be a fundamental downstream effector for ghrelin's modulation of NPY/AgRP neuronal activity. NPY then inhibits both ARC POMC neurons as well as PVN corticotrophin- and thyrotropin-releasing hormone positive anorectic neurons, leading to increased food intake. Intracellular cannabinoids and an intact CB1 receptor are required for the inhibitory effect of ghrelin on PVN neuronal activity.

\section{Outstanding questions}

In this complex landscape, however, several questions remain to be answered and a few controversies to be clarified.

Anderson et al. (2008) showed the effect of ghrelin on CaMKK2-AMPK to be confined to the ARC, whereas the study from Lopez et al. (2008) showed a ghrelin-activated AMPK-FAS pathway only in the VMN. GHSR is expressed in both nuclei and ghrelin stimulates AMPK activity in both the ARC and the VMN (Anderson et al. 2008, Lopez et al. 2008). Thus, how could the ghrelin-induced AMPKdependent reduction in FAS activity and expression be restricted only to the VMN? While Lopez et al. could not show a similar situation for the other nuclei, it seems difficult to accept that while ghrelin induces AMPK activity also in other nuclei such as the ARC, no further downstream effects on the fatty acid pathway components are to be seen here. In fact, we have shown increased pACC in whole hypothalamus (Kola et al. 2005) and Andrews et al. (2008) did show an increased CPT1 activity in the ARC following ghrelin treatment.

Does CaMKK truly mediate the stimulatory effect of ghrelin only in the ARC? If this is the case, how could we then explain the increased AMPK activity observed in VMN? Different experimental settings and the difficulty of obtaining specific data for the different hypothalamic nuclei could confound the interpretation of the pathway.

AMPK activation or inactivation seems to have not just tissue-specific but also cell-dependent effects. Losing AMPK in orexigenic AgRP neurons (AgRP $\alpha$-2-AMPK-KO) leads to reduced body weight, whereas loss of the enzyme in anorexigenic POMC neurons (POMC $\alpha$-2-AMPK-KO) leads to increased body weight (Claret et al. 2007). This adds further support to the tissue-specific effects mentioned earlier.

Do cannabinoids form a separate parallel signalling pathway converging at the level of the AMPK, or are cannabinoids a 
required integrated part of the ghrelin- $\mathrm{Ca}^{2+}$-endocannabinoid-CB1-Ca ${ }^{2+}$-CaMKK-AMPK-malonyl-CoA-CPT1$\beta$-oxidation-ROS-UCP2-NPY/AgRP-food intake pathway? It would be interesting to see if cannabinoid antagonists or lack of CB1 receptor would block the effect of ghrelin on UCP2 expression and activity. Do cannabinoids themselves use the same designated pathway to induce food intake?

Increased $\beta$-oxidation in the ARC seems to provide the necessary bioenergetics for electrical activity of ARC NPY/AgRP neurons. We do not know, however, how UCP2 activation stimulates NPY/AgRP transcription and activation. Does the same paradigm apply to anorexigenic PVN neurons? Or vice versa, do the intracellular cannabinoids, which modulate electrical activity in the PVN, influence the activity of neurons in the ARC or other nuclei? And finally, is this the only pathway through which ghrelin, possibly cannabinoids and other AMPK activators, lead to increased food intake? Does ghrelin influence neuronal activity only through the AMPK-induced $\beta$-oxidation or does AMPK lead to other collateral pathways influencing the final effect of orexigenic and anorexigenic hormones?

While we have restricted ourselves here to a discussion of the hypothalamic effects of ghrelin, another intriguing issue that deserves further attention is the role of central ghrelin, AMPK, and their hypothalamic downstream effectors in the modulation of peripheral metabolism. Central ghrelin treatment influences peripheral adipose tissue metabolism, probably through the sympathetic nervous system (Theander-Carrillo et al. 2006). Chronic central ghrelin infusion resulted in increased mRNA expression of various fat storage-promoting enzymes such as lipoprotein lipase, ACC, FAS, and reduction of CPT1 expression in white adipose tissue. These changes are indeed in the opposite direction of those seen in the hypothalamic fatty acid pathway after ghrelin treatment. This is not surprising as the effect of ghrelin on AMPK is tissue-specific; we have found that i.p. and i.c.v. ghrelin decreases AMPK activity in adipose tissue ((Kola et al. 2005) and Kola \& Korbonits unpublished data), while it stimulates it in the hypothalamus. In brown adipocytes, central ghrelin treatment lowered expression of UCP1 and UCP3. Interestingly, the effects of central ghrelin on white and brown adipose tissue occurred independently of ghrelin-induced hyperphagia (Theander-Carrillo et al. 2006).

Malonyl-CoA signal is transmitted from the brain to the skeletal muscle (Cha et al. 2005) and hypothalamic AMPK modulates peripheral hormonal counter-regulatory response to hypoglycaemia and is implicated in the effect of central leptin to the skeletal muscle (Kola 2008). Are therefore hypothalamic signalling molecules such as AMPK, ACC, FAS, CPT1, UCP2, and cannabinoids determinants of this other aspect of ghrelin's physiology?

As we discover novel pathways and mechanisms, new questions arise regarding the intricate regulation of appetite.
However, the rising impact of obesity on health in both developed and developing societies renders our understanding of these processes of fundamental importance and a major priority for future research.

\section{Declaration of interest}

The authors declare that there is no conflict of interest that could be perceived as prejudicing the impartiality of the research reported.

\section{Funding}

This work was supported by the Wellcome Trust Project Grant 081922/Z/07/Z

\section{References}

Anderson KA, Ribar TJ, Lin F, Noeldner PK, Green MF, Muehlbauer MJ, Witters LA, Kemp BE \& Means AR 2008 Hypothalamic CaMKK2 contributes to the regulation of energy balance. Cell Metabolism 7 377-388.

Andersson U, Filipsson K, Abbott CR, Woods A, Smith K, Bloom SR, Carling D \& Small CJ 2004 AMP-activated protein kinase plays a role in the control of food intake. Journal of Biological Chemistry 279 12005-12008.

Andrews ZB, Liu ZW, Wallingford N, Erion DM, Borok E, Friedman JM, Tschop MH, Shanabrough M, Cline G, Shulman GI et al. 2008 UCP2 mediates ghrelin's action on NPY/AgRP neurons by lowering free radicals. Nature 454 846-851.

Barazzoni R, Bosutti A, Stebel M, Cattin MR, Roder E, Visintin L, Cattin L, Biolo G, Zanetti M \& Guarnieri G 2005 Ghrelin regulates mitochondriallipid metabolism gene expression and tissue fat distribution in liver and skeletal muscle. American Journal of Physiology. Endocrinology and Metabolism 288 E228-E235.

Bennett PA, Thomas GB, Howard AD, Feighner SD, Van der Ploeg LH, Smith RG \& Robinson IC 1997 Hypothalamic growth hormone secretagogue-receptor (GHS-R) expression is regulated by growth hormone in the rat. Endocrinology 138 4552-4557.

Cha SH, Hu Z, Chohnan S \& Lane MD 2005 Inhibition of hypothalamic fatty acid synthase triggers rapid activation of fatty acid oxidation in skeletal muscle. PNAS 102 14557-14562.

Chakravarthy MV, Zhu Y, Lopez M, Yin L, Wozniak DF, Coleman T, Hu Z, Wolfgang M, Vidal-Puig A, Lane MD et al. 2007 Brain fatty acid synthase activates PPARalpha to maintain energy homeostasis. Journal of Clinical Investigation 117 2539-2552.

Claret M, Smith MA, Batterham RL, Selman C, Choudhury AI, Fryer LG, Clements M, Al Qassab H, Heffron H, Xu AW et al. 2007 AMPK is essential for energy homeostasis regulation and glucose sensing by POMC and AgRP neurons. Journal of Clinical Investigation 117 2325-2336.

Cowley MA, Smith RG, Diano S, Tschop M, Pronchuk N, Grove KL, Strasburger CJ, Bidlingmaier M, Esterman M, Heiman ML et al. 2003 The distribution and mechanism of action of ghrelin in the CNS demonstrates a novel hypothalamic circuit regulating energy homeostasis. Neuron 37 649-661.

Cummings DE, Purnell JQ, Frayo RS, Schmidova K, Wisse BE \& Weigle DS 2001 A preprandial rise in plasma ghrelin levels suggests a role in meal initiation in humans. Diabetes 50 1714-1719.

Egecioglu E, Stenstrom B, Pinnock SB, Tung LY, Dornonville de la CC, Lindqvist A, Hakanson R, Syversen U, Chen D \& Dickson SL 2008 Hypothalamic gene expression following ghrelin therapy to gastrectomized rodents. Regulatory Peptides 146 176-182. 
Faulconbridge LF, Grill HJ, Kaplan JM \& Daniels D 2008 Caudal brainstem delivery of ghrelin induces fos expression in the nucleus of the solitary tract, but not in the arcuate or paraventricular nuclei of the hypothalamus. Brain Research 1218 151-157.

Guan X-M, Yu H, Palyha OC, McKee KK, Feighner SD, Sirinathsinghji DJS, Smith RG, Van der Ploeg LHT \& Howard AD 1997 Distribution of mRNA encoding the growth hormone secretagogue receptor in brain and peripheral tissues. Molecular Brain Research 48 23-29.

Hawley SA, Pan DA, Mustard KJ, Ross L, Bain J, Edelman AM, Frenguelli BG \& Hardie DG 2005 Calmodulin-dependent protein kinase kinase-beta is an alternative upstream kinase for AMP-activated protein kinase. Cell Metabolism 2 9-19.

He W, Lam TK, Obici S \& Rossetti L 2006 Molecular disruption of hypothalamic nutrient sensing induces obesity. Nature Neuroscience 9 227-233.

Higgins SC, Gueorguiev M \& Korbonits M 2007 Ghrelin, the peripheral hunger hormone. Annals of Medicine 39 116-136.

Kim MS, Park JY, Namkoong C, Jang PG, Ryu JW, Song HS, Yun JY, Namgoong IS, Ha J, Park IS et al. 2004 Anti-obesity effects of alpha-lipoic acid mediated by suppression of hypothalamic AMP-activated protein kinase. Nature Medicine 10 727-733.

Kirkham TC \& Tucci SA 2006 Endocannabinoids in appetite control and the treatment of obesity. CNS and Neurological Disorders Drug Targets 5 272-292.

Kohno D, Sone H, Minokoshi Y \& Yada T 2008 Ghrelin raises $\left[\mathrm{Ca}^{2+}\right]_{\mathrm{i}}$ via AMPK in hypothalamic arcuate nucleus NPY neurons. Biochemical and Biophysical Research Communications 366 388-392.

Kojima M, Hosoda H, Date Y, Nakazato M, Matsuo H \& Kangawa K 1999 Ghrelin is a growth-hormone-releasing acylated peptide from stomach. Nature 402 656-660.

Kola B 2008 Role of AMP-activated protein kinase in the control of appetite. Journal of Neuroendocrinology 20 942-951.

Kola B, Hubina E, Tucci SA, Kirkham TC, Garcia EA, Mitchell SE, Williams LM, Hawley SA, Hardie DG, Grossman AB et al. 2005 Cannabinoids and ghrelin have both central and peripheral metabolic and cardiac effects via AMP-activated protein kinase. Journal of Biological Chemistry 280 25196-25201.

Kola B, Boscaro M, Rutter GA, Grossman AB \& Korbonits M 2006 Expanding role of AMPK in endocrinology. Trends in Endocrinology and Metabolism 17 205-215.

Kola B, Farkas I, Christ-Crain M, Wittmann G, Lolli F, Amin F, Harvey-White J, Liposits Z, Kunos G, Grossman AB et al. 2008 The orexigenic effect of ghrelin is mediated through central activation of the endogenous cannabinoid system. PLoS ONE 3 e1797.

Kubota N, Yano W, Kubota T, Yamauchi T, Itoh S, Kumagai H, Kozono H, Takamoto I, Okamoto S, Shiuchi T et al. 2007 Adiponectin stimulates AMP-activated protein kinase in the hypothalamus and increases food intake. Cell Metabolism 6 55-68.

Lage R, Dieguez C, Vidal-Puig A \& Lopez M 2008 AMPK: a metabolic gauge regulating whole-body energy homeostasis. Trends in Molecular Medicine 14 539-549.

Landree LE, Hanlon AL, Strong DW, Rumbaugh G, Miller IM, Thupari JN, Connolly EC, Huganir RL, Richardson C, Witters LA et al. 2004 C75, a fatty acid synthase inhibitor, modulates AMP-activated protein kinase to alter neuronal energy metabolism. Journal of Biological Chemistry 279 $3817-3827$.

Loftus TM, Jaworsky DE, Frehywot GL, Townsend CA, Ronnett GV, Lane MD \& Kuhajda FP 2000 Reduced food intake and body weight in mice treated with fatty acid synthase inhibitors. Science 288 2379-2381.

Lopez M, Lelliott CJ, Tovar S, Kimber W, Gallego R, Virtue S, Blount M, Vazquez MJ, Finer N, Powles TJ et al. 2006 Tamoxifen-induced anorexia is associated with fatty acid synthase inhibition in the ventromedial nucleus of the hypothalamus and accumulation of malonyl-CoA. Diabetes $\mathbf{5 5}$ 1327-1336.

Lopez M, Lage R, Saha AK, Perez-Tilve D, Vazquez MJ, Varela L, Sangiao-Alvarellos S, Tovar S, Raghay K, Rodriguez-Cuenca S et al. 2008 Hypothalamic fatty acid metabolism mediates the orexigenic action of ghrelin. Cell Metabolism 7 389-399.
Di Marzo V, Goparaju SK, Wang L, Liu J, Batkai S, Jarai Z, Fezza F, Miura GI, Palmiter RD, Sugiura T et al. 2001 Leptin-regulated endocannabinoids are involved in maintaining food intake. Nature 410 822-825.

Minokoshi Y, Alquier T, Furukawa N, Kim YB, Lee A, Xue B, Mu J, Foufelle F, Ferre P, Birnbaum MJ et al. 2004 AMP-kinase regulates food intake by responding to hormonal and nutrient signals in the hypothalamus. Nature 428 569-574.

Momcilovic M, Hong SP \& Carlson M 2006 Mammalian TAK1 activates Snf1 protein kinase in yeast and phosphorylates AMPactivated protein kinase in vitro. Journal of Biological Chemistry 281 25336-25343.

Neary NM, Druce MR, Small CJ \& Bloom SR 2006 Acylated ghrelin stimulates food intake in the fed and fasted states but desacylated ghrelin has no effect. Gut 55135.

Obici S, Feng Z, Arduini A, Conti R \& Rossetti L 2003 Inhibition of hypothalamic carnitine palmitoyltransferase- 1 decreases food intake and glucose production. Nature Medicine 9 756-761.

Pocai A, Lam TK, Obici S, Gutierrez-Juarez R, Muse ED, Arduini A \& Rossetti L 2006 Restoration of hypothalamic lipid sensing normalizes energy and glucose homeostasis in overfed rats. Journal of Clinical Investigation 116 1081-1091.

Qi J, Gong J, Zhao T, Zhao J, Lam P, Ye J, Li JZ, Wu J, Zhou HM \& Li P 2008 Downregulation of AMP-activated protein kinase by Cidea-mediated ubiquitination and degradation in brown adipose tissue. EMBO Journal 27 1537-1548.

Sanders MJ, Grondin PO, Hegarty BD, Snowden MA \& Carling D 2007 Investigating the mechanism for AMP activation of the AMP-activated protein kinase cascade. Biochemical Journal 403 139-148.

Seoane LM, Lopez M, Tovar S, Casanueva FF, Senaris R \& Dieguez C 2003 Agouti-related peptide, neuropeptide $\mathrm{Y}$, and somatostatin-producing neurons are targets for ghrelin actions in the rat hypothalamus. Endocrinology 144 544-551.

Shiiya T, Nakazato M, Mizuta M, Date Y, Mondal MS, Tanaka M, Nozoe S, Hosoda H, Kangawa K \& Matsukura S 2002 Plasma ghrelin levels in lean and obese humans and the effect of glucose on ghrelin secretion. Journal of Clinical Endocrinology and Metabolism 87 240-244.

Smith RG, Jiang H \& Sun Y 2005 Developments in ghrelin biology and potential clinical relevance. Trends in Endocrinology and Metabolism 16 436-442.

Sun Y, Asnicar M, Saha PK, Chan L \& Smith RG 2006 Ablation of ghrelin improves the diabetic but not obese phenotype of ob/ob mice. Cell Metabolism 3 379-386.

Suzuki A, Kusakai G, Kishimoto A, Shimojo Y, Ogura T, Lavin MF \& Esumi H 2004 IGF-1 phosphorylates AMPK-alpha subunit in ATM-dependent and LKB1-independent manner. Biochemical and Biophysical Research Communications 324 986-992.

Takahashi KA, Smart JL, Liu H \& Cone RD 2004 The anorexigenic fatty acid synthase inhibitor, C75, is a nonspecific neuronal activator. Endocrinology 145 184-193.

Theander-Carrillo C, Wiedmer P, Cettour-Rose P, Nogueiras R, Perez-Tilve D, Pfluger P, Castaneda TR, Muzzin P, Schurmann A, Szanto I et al. 2006 Ghrelin action in the brain controls adipocyte metabolism. Journal of Clinical Investigation 116 1983-1993.

Tschöp M, Smiley DL \& Heiman ML 2000 Ghrelin induces adiposity in rodents. Nature $\mathbf{4 0 7} 908-913$.

Tsubone T, Masaki T, Katsuragi I, Tanaka K, Kakuma T \& Yoshimatsu H 2005 Ghrelin regulates adiposity in white adipose tissue and UCP1 mRNA expression in brown adipose tissue in mice. Regulatory Peptides 130 97-103.

Wolfgang MJ, Kurama T, Dai Y, Suwa A, Asaumi M, Matsumoto S, Cha SH, Shimokawa T \& Lane MD 2006 The brain-specific carnitine palmitoyltransferase-1c regulates energy homeostasis. PNAS $1037282-7287$.

Woods A, Dickerson K, Heath R, Hong SP, Momcilovic M, Johnstone SR, Carlson M \& Carling D $2005 \mathrm{Ca}^{2+} /$ calmodulin-dependent protein kinase kinase-beta acts upstream of AMP-activated protein kinase in mammalian cells. Cell Metabolism 2 21-33. 
Wu Z, Puigserver P, Andersson U, Zhang C, Adelmant G, Mootha V, Troy A, Cinti S, Lowell B, Scarpulla RC et al. 1999 Mechanisms controlling mitochondrial biogenesis and respiration through the thermogenic coactivator PGC-1. Cell 98 115-124.

Yang J, Brown MS, Liang G, Grishin NV \& Goldstein JL 2008 Identification of the acyltransferase that octanoylates ghrelin, an appetite-stimulating peptide hormone. Cell 132 387-396.

Zhou G, Myers R, Li Y, Chen Y, Shen X, Fenyk-Melody J, Wu M, Ventre J, Doebber T, Fujii N et al. 2001 Role of AMP-activated protein kinase in mechanism of metformin action. Journal of Clinical Investigation 108 1167-1174.
Zigman JM, Nakano Y, Coppari R, Balthasar N, Marcus JN, Lee CE, Jones JE, Deysher AE, Waxman AR, White RD et al. 2005 Mice lacking ghrelin receptors resist the development of diet-induced obesity. Journal of Clinical Investigation 115 3564-3572.

Received in final form 5 March 2009

Accepted 19 March 2009

Made available online as an Accepted Preprint 20 March 2009 